\title{
Failure Analysis of Distributor Gear
}

\author{
Ibrahim Yavuz ${ }^{1 *}$ \\ 0000-0002-4480-2342 \\ ${ }^{1}$ Automotive Engineering Department, Faculty of Technology, Afyon Kocatepe University, Afyon, 03200, Turkey
}

\begin{abstract}
This study experimentally and theoretically investigated the fracture damage on the distributor gear of a front-wheel drive automobile. The experimental studies initially analyzed the fracture surfaces of the gear in the scanning electron microscope (SEM). Subsequently, microstructure analysis and mechanical tests were performed. In the theoretical study, on the other hand, static analyses were performed using the finite element method on the ANSYS software program. Static analyses revealed equivalent stresses on the piece and determined its critical regions. Finally, the theoretical and experimental studies were compared with literature data. As a result, the occurrence of a ductile fracture was observed and it was determined to be the area where the most critical fracture occurred.
\end{abstract}

Keywords: Failure Analysis, Distributor Gear, Finite Element Method, Fatigue
Research Article

https://doi.org/10.30939/ijastech..823415

$\begin{array}{lr}\text { Received } & 09.11 .2020 \\ \text { Revised } & 21.01 .2021\end{array}$

Accepted 03.02.2021

* Corresponding author

Ibrahim Yavuz

iyavuz@aku.edu.tr

Address: Automotive Engineering Department, Faculty of Technology, Afyon Kocatepe University, Afyon, Turkey

Tel:+902722182547

Fax:+90 2722182693

\section{Introduction}

The automotive and computer industry has gained importance due to the developments in the industry. Developments in the automotive sector depend on the economy and security. Due to the advancement of technology, new systems or components are added to vehicles. Hence, the vehicles of today are more complex than old models. Despite the developments in technology, internal combustion engines are still widely used today. There are two kinds of internal combustion engines, distinguished on their working principles; Otto and diesel. Diesel engines are ignited by the fuel injected into the compressed air while the fuel-compressed air mixture in Otto engines is ignited by means of a separate ignition system. Hence, the ignition system is one of the most important systems for the Otto engines to work.

Coil, distributor shafts, spark plugs and cables are some of the main parts of the ignition system. The task of distributors is to send the high electric voltage that takes place in the ignition coil, to the spark plug in the cylinder in the correct firing order. Distributor shafts need to be driven regularly to fulfill this task. Since this drive is, in different ways, dependent on the design of the engines, the distributor shafts are either driven directly by a camshaft or by a gear on the camshaft. In some vehicles, the distributor shaft may also drive the oil pump. The gear in question is of such a vehicle (Fig 1).
Despite the developments in materials technology, some cracks, fracture or wear can be observed in some parts of vehicles due to factors such as fatigue and lack of maintenance. Cyclically varying stresses can cause some damage to the internal structure of the material. Thus, the damage occurs far below the static limit. Lifetime refers to the time through which the element endures until it breaks due to the changes in the internal structure of the material under the influence of varying stresses and fatigue.

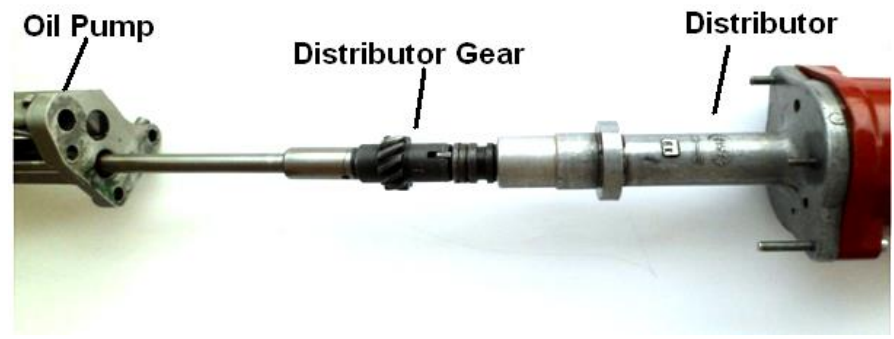

Fig. 1. Oil pump and distributor gear mechanism

The lifetime of the element is usually described by the number of cycles. The damage due to varying stresses starts from a point of discontinuity either in the internal structure or on the outer surface. The material around this point becomes fatigued and a crack 
occurs. Over time, this crack deepens and eventually the stress in the region around the crack exceeds the tensile strength and causes the sudden breakage of the element. These damages are examined with different methods and analysis in order to minimize them.

The first visual control of the gear revealed that one tooth was completely broken and the other one was partly fractured. Gears can fail in many different ways [1-3], incorporate fatigue [4,5], wear, impact fracture and stress rupture [6]. Some of the studies on failure analysis are as follows; Among these, Heyes (1998) have shown that the parts that most often fail are in the engine, and its components make up $41 \%$ of automotive failures. This is followed by transmission failures (26\%). Studies on power train investigated the axle shaft and shaft shank. They determined that the damage to the axle shaft was caused by heat treatment, while the damage to the shaft shank was caused by some defect in the design $[8,9]$.

\section{Experimental procedure}

Table 2. Comparison of distributor gear material and ductile iron torsion grade [10].

\begin{tabular}{c|c|c|c|c|c|c|c|c|c|c|c|c}
\hline Element & $\mathrm{Fe}$ & $\mathrm{C}$ & $\mathrm{Si}$ & $\mathrm{Mn}$ & $\mathrm{Cu}$ & $\mathrm{Cr}$ & $\mathrm{Ni}$ & $\mathrm{Mo}$ & $\mathrm{Ce}$ & $\mathrm{Mg}$ & $\mathrm{P}$ & $\mathrm{S}$ \\
\hline $\begin{array}{c}\% \\
\text { Compound }\end{array}$ & 92,8 & 3,48 & 2,21 & 1.03 & 0,158 & 0,0204 & 0,0662 & 0,008 & 0,0023 & 0,0073 & 0,0214 & 0,0498 \\
\hline D.I.T.G & $\mathrm{Fe}$ & $\mathrm{C}$ & $\mathrm{Si}$ & $\mathrm{Mn}$ & $\mathrm{Cu}$ & $\mathrm{Cr}$ & $\mathrm{Ni}$ & $\mathrm{Mo}$ & $\mathrm{Ce}$ & $\mathrm{Mg}$ & $\mathrm{P}$ & $\mathrm{S}$ \\
\hline$\%$ & 90,74 & 3,60 & 1,80 & 0,15 & 0,15 & 0,030 & 0,050 & 0,010 & 0,0050 & 0,030 & $\leq 0,030$ & $\leq 0,0020$ \\
Compound & 94,18 & 3,80 & 2,80 & 1,0 & 1,0 & 0,070 & 0,20 & 0,10 & 0,20 & 0,060 & $\leq 0$ \\
\hline
\end{tabular}

\subsection{Microstructure analysis}

Figure 2 seen that the ferrite structures in the pearlitic matrix microstructure are surrounded by graphite nodules. The matrix is ductile cast iron. The specific shape of graphite in the ferritic microstructure acts as a crack stopper and lowers the stress density in front of the crack, making it a suitable material for such cyclically loaded structures.

The roundness of graphites in ferritic microstructure reduces crack propagation and stress end. This microstructure feature adds impact resistance to ductile iron cast iron. [11-15]. Perlite is a product of ferrite with a carbide structure called cementite. There are two phases in thin layers in the perlite structure. So actually, the pearlite is not a single phase, it is more accurate as a combined joint of the two phases (cementite and ferrite). This structure creates a higher strength and hardness of ferrite, as the thin carbide layers of perlite support the thin ferrite layers arranged together [16]. It is required that the resistance to this demand is high, the perlite ratio in the casting should be increased. As a natural result of this increase in strength, it is observed that the ductility of cast iron with pearlitic structure has decreased a little.

\subsection{Mechanical properties}

The average hardness value was determined using the Vickers hardness measurement method under $980 \mathrm{~N}$ loads is $225.45 \mathrm{HV}$. Mechanical properties of ductile cast iron are given in Table 1. Chemical analysis of the internal structure reveals that it is a Fe-C-Si alloy. They generally contain $2.5-4.5 \% \mathrm{C}, 1-3.5 \% \mathrm{Si}$ and $1.03 \% \mathrm{Mn}$. The element ratios of the internal structure according to spectral analysis are as follows; As can be seen, the material contains $3.48 \% \mathrm{C}$, $2.21 \% \mathrm{Si}, 1.03 \% \mathrm{Mn}, 0.214 \% \mathrm{P}$ and other contributing elements at various ratios (Table 2).

Table 1. Mechanical properties of ductile iron torsion grade [10].

\begin{tabular}{c|c}
\hline Mechanical Properties & Metric \\
\hline Hardness, Vickers & $197-283$ \\
\hline Tensile Strength, Ultimate & $\leq 552 \mathrm{MPa}$ \\
\hline Tensile Strength, Yield & $\leq 379 \mathrm{MPa}$ \\
\hline
\end{tabular}

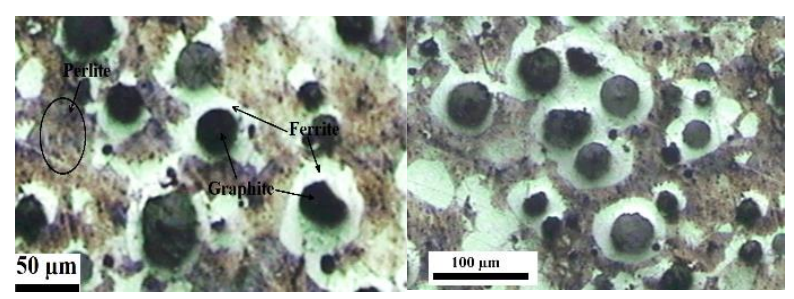

Fig. 2. Optical microscopy images of the distributor gear

\subsection{SEM analysis of fracture surface}

Figure 3 shows the SEM images of the fractured surfaces of the distributor gear. SEM images is shown the progressive flat fatigue fracture region. This surface is the fatigue appearance of cast iron under torsional stress. Fatigue striations and elongation of the nodule cavity could be seen in the crack propagation zone. Mixture of striations and fractured pearlite zone on fracture surfaces are a typical characteristic of fatigue failure of ductile cast irons [17,18].

Fatigue damage in mechanical structures generally starts at notches. Threaded areas, dimensional transitions, rivet holes, weld and keyways, lubrication holes are natural and generally unavoidable notches [19]. This is because the maximum stress is at the notches zone. also, when the distributor gear is in force, the spherical graphite's in the hole area increase the stress concentration. In addition, it is well known that if there are free graphite and nonspheroidal graphite in the microstructure, not only can this lead to 
a high stress concentration, but can also cause fatigue crack start during a short working time [20].

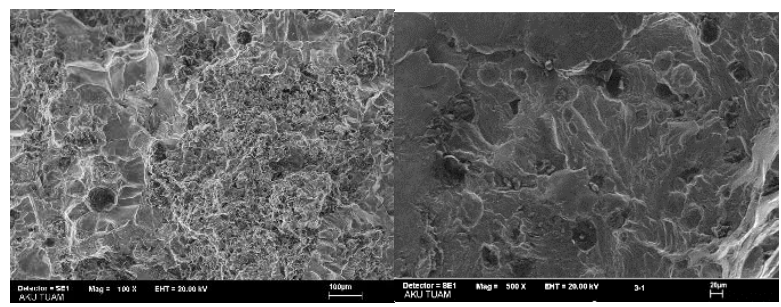

Fig. 3. SEM Images of the distributor gear

It is possible to initiate fatigue cracking when the local stress exceeds the yield strength of the material. Depending on the yield

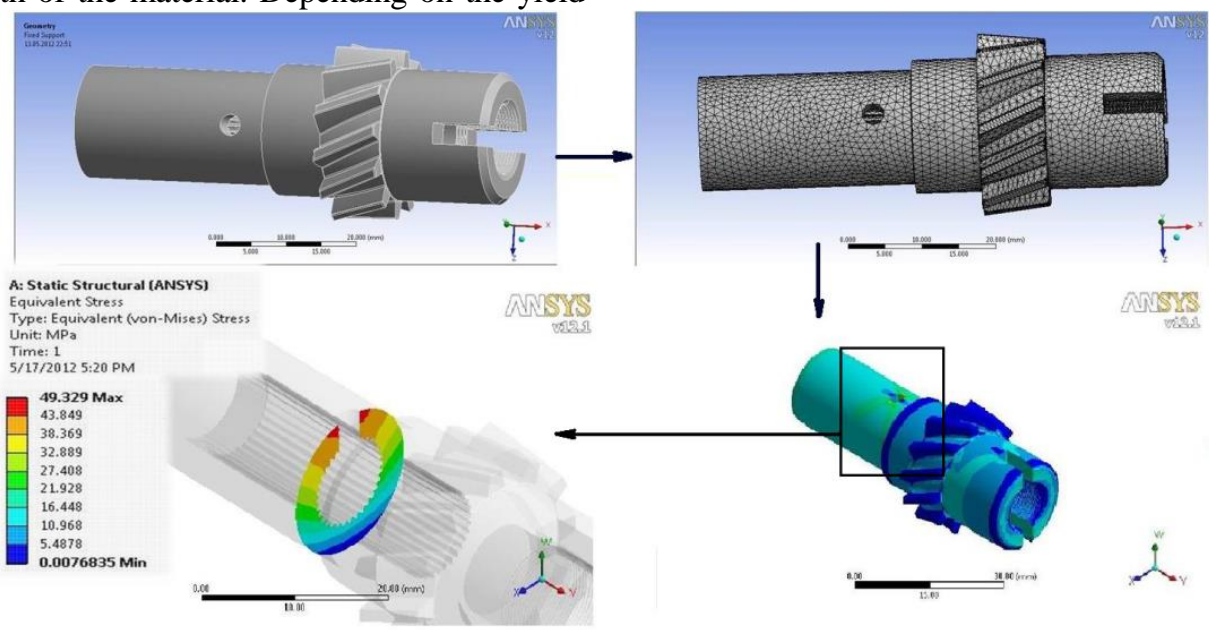

Fig. 4. Finite element analysis of distributor gear

The results of the analysis show that the maximum stress occurred in the whole region. The region where stress concentration occurred was sectioned in order to see the stresses that occurred in the critical region of the part (Fig. 5).
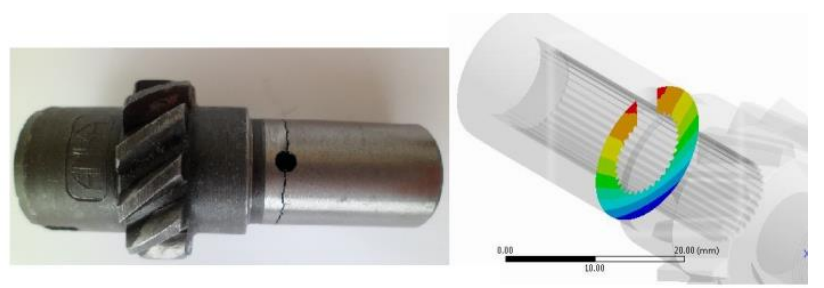

Fig. 5. Images of the distributor gear analysis result and of the damaged part

The results of the analysis showed that the maximum stress occurred on each side of the hole and that similar damage occurred in the part. The stress occurred in a straight line with the axis of the hole and the fractured part indicated that the fractured axis occurred similar to the analysis. strength of the materials, the fatigue strength changes proportionally. The low yield strength of ductile iron is its weakest feature against fatigue cracking [20].

\subsection{Finite element analysis}

Distributor gear was drawn in the Solid Works program and the Ansys finite element program was used for the analysis. $0.75 \mathrm{~mm}$ mesh was implemented in the static analysis model (Fig.4). Distributor gear was mounted on the upper and lower sections and force was applied from the gear surfaces. Figure 4 presents the voltage distribution graph values on 52 points on a line of the sectioned form of the critical region. 


\section{References}

[1] Osman A. Fatigue failure of a helical gear in a gearbox. Eng Fail Anal. 2006; 13: 1116-1125.

[2] Kovan V, Sekercioglu T. Pitting failure of truck spiral bevel gear. Eng Fail Anal. 2007; 14: 614-619.

[3] Park S, Lee L, Moon U, Kim D. Failure analysis of a planetary gear carrier of $1200 \mathrm{HP}$ transmission. Eng Fail Anal. 2010; 17:521-52.

[4] $\mathrm{Yu} \mathrm{Z}, \mathrm{Xu} \mathrm{X}$. Failure investigation of a truck diesel engine gear train consisting of crankshaft and camshaft gears. Eng Fail Anal. 2010; 17: 537-545.

[5] Rivera R, Chiminelli A, Gómez C, Núñez JL. Fatigue failure analysis of a spring for elevator doors. Eng Fail Anal. 2010; 17: 731-738.

[6] Peng C, Liu, Z., Zhu W. Failure analysis of a gear tooth facture of a rolling mill decelerator. Eng Fail Anal. 2011; 18: 25-35.

[7] Heyes AM. Automotive component failures. Eng Fail. Anal. 1998; 2: 129-141.

[8] Bayrakceken H, Tasgetiren S, Yavuz İ. Two cases of failure in the power transmission system on vehicles: A universal joint yoke and a drive shaft. Eng Fail Anal. 2007; 14: 716-724

[9] Yavuz İ, Bayrakçeken H. Failure analysis of a rear axle shaft of an automobile. Electronic Journal of Vehicle Technologies. 2011; 3: 11-19

[10] http://www.matweb.com/search/DataSheet.aspx?MatGUID=d20e4edc37934019b4db18a505723a26\&ckck=1 (2020).

[11] Clement J, Angeli P, Pineau A. Short crack behavior in nodular cast iron. Fatigue \& Fracture of Engineering Materials \& Structures. 1984; 7: 251-265.

[12] Guillemer-Neel C, Bobet V, Clave M. Cyclic deformation behaviour and Bauschinger effect in ductile cast iron. Mater. Sci. Eng. A. 1999; 272: 431-442.

[13] Stokes B, Gao N, Reed PAS. Effects of graphite nodules on crack growth behavior of austempered ductile iron. Mater. Sci. Eng. A. 2007; 445-446, 374-385.

[14] Minnebo P, Nilsson KF, Blagoeva D. Tensile, compression and fracture properties of thick-walled ductile cast iron components. J. Mater. Eng. Perfor. 2007; 16: 35-45.

[15] Xue HQ, Bayraktar E, Bathias C, Mater J. Damage mechanism of a nodular cast iron under the very high cycle fatigue regime. Process. Technol. 2008; 202: 216-223

[16] Canzar P, Tonkovic Z, Kodvanj J. Microstructure influence on fatigue behaviour of nodular cast iron. Materials Science and Engineering: A. 2012; 556: 88-99

[17] Bulloch JH. Fractographic analysis of fatigue cracking in spheroidal graphite cast irons. Theoretical and Applied Fracture Mechanics. 1992; 17: 19-45.

[18] Bebera VC, Schneidera B, Bredea M. On the fatigue behavior of notched structural adhesives with considerations of mechanical properties and stress concentration effects. Procedia Engineering. 2018; 213: 459-469

[19] Asi O. Failure analysis of a crankshaft made from ductile cast iron. Engineering Failure Analysis. 2006; 13(8): 1260-1267
[20] Zambrano OA, Coronado JJ, Rodri'guez SA. Failure analysis of a bridge crane shaft. Case Studies in Engineering Failure Analysis. 2014; 2: 25-32 